\title{
SMART LEARNING OF FUTURE ENGLISH LANGUAGE TEACHERS: STUDENTS' TIME MANAGEMENT AND PERFORMANCE IN AN ONLINE COURSE
}

\author{
Anita Auziña \\ University of Latvia, Latvia
}

\begin{abstract}
An online course can offer limitless opportunities to expand one's knowledge, develop skills and competences and, meanwhile, combine one's online learning journey with a real-world activity, also studies in the case of university students. To manage all, the use of time for the productivity and achievement is crucial. The paper discusses the time management and performance of university students, future English language teachers in particular, taking an online course. A case study was carried out, and teacher education students, who participated in an online course on Learning Technologies and Content and Language Integrated Learning (CLIL), were questionnaired to explore their time management strategies and performance during their five-month online study period. The reflections of the online course moderators were collected to triangulate the data and find out their opinion on students' time management habits and performance quality; besides, the differences between their expectations and reality were examined. Findings suggest that students' time management was considerably challenged, and the set amount of time, i.e. one week to accomplish one module and its related assignments, required advanced planning and change of study habits to achieve the aims and objectives of their online learning process.
\end{abstract}

Keywords: English language teachers, online course, smart learning, time management.

\section{Introduction}

Current range of technologies offer considerable opportunities to being integrated in language education. Computers, smartphones, tablets enhance any language learner's, from a very young learner to an adult, interaction, linguistic immersion and output in a target language. In today's digital age, animated books, automatic speech recognition programmes, chat programmes, sites that offer practise possibilities with a virtual agent allow to enrich a language learner's experience and learn smart that not always is present in a traditional classroom (Golonka, Bowles, 2014; van den Berghe, 
Verhagen, 2019). Therefore, the purpose of the article is to explore how researchers and pre-service teachers approach technologies, innovations, online and smart learning in language education from a theoretical and empirical perspective.

Inevitably, educational technology and online activities are strongly embedded as a part of current language teachers' toolkits. A fundamental knowledge a teacher should have, according to Council of Europe (2019), is related to learners':

- being online - information related to how one engages and exists online, "it comprises three digital domains: access and inclusion, learning and creating, media and information literacy";

- well-being online - information related to how one feels online, "comprising another three digital domains: ethics and empathy, health and well-being, e-presence and communication";

- rights online - "information related to being accountable online, comprising four digital domains: active participation, rights and responsibilities, privacy, security and consumer awareness" (p. 11).

It is a crucial and good practice to highlight above listed digital domains in the teacher education to deepen pre-service teachers' understanding of the digital citizenship and relate it to their future classroom practices and professional activities.

Moreover, educators are to consider continuously how to blend a traditional form of education with technology-enhanced learning, also called smart learning, being aware and open to various intelligent tutoring systems, seriously considering how to apply technologies in the education process to promote learning (Daniela, Kalnina, 2017). Hwang (2014) indicates that "a smart learning environment not only enables learners to access digital resources and interact with learning systems in any place and at any time, but also actively provides the necessary learning guidance, hints, supportive tools or learning suggestions to them in the right place, at the right time and in the right form" (p. 2). A smart combination can help students to learn in a smart way, too. Besides, Thompson (2017) suggests seeking "to connect academic learning to students' out-of-school technology use" (p. 257).

Striving to improve educational outcomes, meanwhile, considering how to manage expenses at the higher education institution is a long-term discussion referred to teaching smaller groups of students, especially in less popular but still essential fields of science. A favourable opportunity could be more enhancing and strengthening professional core knowledge and competences through students' autonomous work, studying carefully and mindfully designed learning materials and completing more autograded assignments in an online course format, reducing contact with lecturers. 
However, the author of the paper suggests a blended learning approach as some interaction, even if it is a distance interaction, of a group of students and the academic staff via appropriate communication tools could be a valuable and notable contribution.

Undoubtedly, online courses can offer limitless opportunities to expand one's knowledge, develop skills and competences in a timeless time, in the 24-by-7 world, and combine one's online learning journey with a realworld activity. The question is whether it is appropriate for any type of a student and whether every individual is skilful to manage one's time to plan and make effort in order to achieve the aims and objectives effectively. To draw parallels, a number of studies have already indicated that barely anyone who starts an online course also completes it (Koller, Ng, 2013; Reich, 2014; Murray, 2019; Reich, Ruiperez-Valiente, 2019) when the initial curiosity fades and the stated intentions change.

Time management and its impact on students' performance could be examined closer as factors to determine one's devotion to the learning process and completion of what has been started. Lakein (1973) saw time management as the process of determining needs, setting goals to achieve the determined needs, prioritising and planning the tasks required to achieve the settled goals. In Thompson's (2017) study, the time management is measured describing how students organise their time on a macro-level, assigning adequate time to study. In the context of initiated learning in an online environment that has to be combined with different real-world activities and studies, in the case of university students, it can be challenging when searching how to make better use of one's time. Claessens, van Eerde (2007) consider that practice and training can enhance time management skills, but not support them directly and automatically to the performance as to become better. Thus, one has to contemplate on how to plan, prioritise, also control activities on a daily basis to manage what has been intended to be accomplished.

\section{Methodology and Materials}

To let university students explore theoretical underpinnings of classroom-based technologies, smart learning environments, digital study tools, computer-assisted language learning, synchronous and asynchronous communication and, meanwhile, have hands on practice participating in an online course, a group of future English language teachers of the University of Latvia $(n=30)$ volunteered to participate in a case study. The online course entitled "Learning Technologies and Content and Language Integrated Learning (CLIL)" was organised in cooperation between the British Council and the University of Latvia and was moderated by 
2 representatives of the British Council. The online course participants were explained that the online course was specially designed to meet the learning outcomes of the particular semester when future English language teachers had to acquire the knowledge and skills of integrating, first, technology in the language learning and, second, the English language skills into other subjects using a methodology of CLIL. Hence, 6 ECTS (European Credit Transfer System) credits could be awarded for the completed online course as a substitution of two other planned study courses (of 3 ECTS credits each), introducing a similar content.

The online course was held for a five-month study period (18 weeks in total) in an online platform developed by the British Council (cpd.english. britishcouncil.org). The course consisted of the following elements:

- 16 thematic modules with relevant units presenting theoretical standpoints;

- videos of experts in the field and in-service teachers;

- examples of lesson plans where the usage of learning technologies for developing core skills was demonstrated;

- activities to check one's understanding of the learning points with a help of different types of questions (true or false, drag and drop, matching pairs, multiple choice textual clues, find in infographics, sentence sequencing, fill-in-the-blanks, open-ended and closed-ended questions);

- addition resources for further reading;

- weekly emails;

- weekly forum discussions (15 in total);

- 3 independent assignments where participants demonstrated how they could apply the new ideas from the online course into language lesson plans, then testing them in a real classroom and reflecting on the gained experience (what went well? what did not go well? what changes have to be made next time? why?);

- 2 synchronous sessions, i.e. webinars, offering a chance to ask any questions about the course and to learn more about effective studying online.

When indicating the learning outcomes, by the end of the whole online course students had to have a better understanding of cyber well-being, digital literacy, evaluation and integration of website, social networks for educational use and development of the English language skills, and meet the methodological challenges when designing English lesson plans for combining a physical classroom work with online learning environments.

At the end of the online course its participants completed a questionnaire to explore their performance, time management strategies and challenges during their five-month online study period. The questionnaire consisted 
of closed-ended, the Likert scale, and open-ended questions. The current paper focuses on a deeper analysis of the gained results. Besides, particular attention was paid to the triangulation process to provide reliable and valid findings. Thus, reflections upon the gained experience and viewpoints from two online course moderators representing the British Council were collected during an online meeting.

The study was a qualitative research where the researcher was also an active online course participant. The researcher volunteered to participate in the project, too, to collaborate with the online course moderators and complete the modules together with her students. Thus, it allowed the researcher to have a more in-depth insight into the online learning process and support students locally and in a real life setting when needed. Circumstantially, the last objective considerably affected the research results, which are discussed in the upcoming section of the paper.

\section{Results and Discussions}

The participation in the offered online course was not meant to limit the amount of students' leisure time. Although it replaced two real time study courses, the platform, their smart learning environment, helped students to gain knowledge even when they had their leisure hours and were in their own real-world environment in which they were located in. This case study provides an account of one group's experience, thus the case shed light on the challenges of university students' time management strategies and performance in the online learning process.

There were 30 participants (23 female and 7 male, aged 22-39) involved in the online course, divided in two groups with 15 participants in each per moderator, representing the British Council. The moderator regularly, i.e. weekly, sent emails informing about the thematic module of the week, as it was planned that one module had to be studied within one-week period. In the learning platform, the moderator regularly contributed with feedback, comments and additional questions to the participants' posts in weekly forum discussions.

According to the study plan, the moderators organised two webinars, first, for getting acquainted and leading into the online learning process on the British Council designed platform (cpd.english.britishcouncil.org), second, for addressing burning questions related to study challenges students faced or discussing more academic and fundamental questions on the covered topics of the course, thus enriching the understanding on technology-enhanced language learning and the effectiveness of its impact. However, the webinar participation rate was not high (45-80\% of students); it could be closely related to the moderator's choice to plan 
them on a Friday evening and on a Saturday or Sunday morning, which is the time when students typically are busy having social activities with peers. To conclude, the time for webinars has to be planned rationally to have a high participation rate.

Having in mind the previously discussed completion rate tendencies of other open online courses (Koller, Ng, 2013; Reich, 2014; Murray, 2019; Reich, Ruiperez-Valiente, 2019), the researcher examined the obtained results. Figure 1 shows that the completion rate of the offered online course was $63 \%$, i.e. 19 out of 30 participants. It is worth noting that those 12 students, which the researcher met on regular basis during other study courses based at the university and had a chance to inquire in person about the issues they had in the learning process or when doing individual assignments, completed the online course entirely (100\%). It leads to a conclusion that a blended rather than a totally online learning approach is meaningful and beneficial; even when planning to reduce expenses for teaching smaller groups of students at the university, face-toface interaction meetings have to be organised.

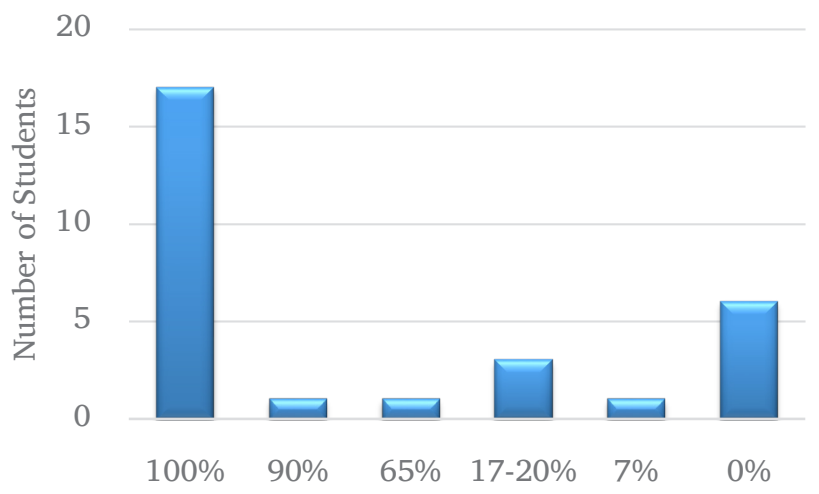

Figure 1. The Online Course Completion Rate among Students

The group of students $(n=8)$ who hardly participated in the online course (the contribution of $20 \%$ and less) or withdrew $(n=3)$ from the course, failed the course and had to attend the original study courses at the university the upcoming semester. Among the reasons to withdraw from the course students declared the following: a lack of knowledge on using the learning platform in their study process participating in such an online course for the first time (and hesitated to admit it and search for support), an overload in studies, a lack of time or limited time management skills, a lack of intention to complete the online course. These reasons correlate with the results of other studies (Koller, $\mathrm{Ng}$, 2013; Reich, 2014; Murray, 2019; Reich, Ruiperez-Valiente, 2019) on predictors of completing open 
online courses. The language barrier was declined; although the online course was designed and delivered in the English language, the future English teachers perceived theoretical concepts and comprehended the course contents well.

Studying closer the students' performance, the final grades were given using an IELTS (International English Language Testing System) style band score rating (2-10), where Band 10 was the highest score and was given to participants who had completed all the modules, submitted three independent assignments (plans for technology-enhanced English lessons) and participated in the forum discussions. Correspondingly, Band 2 was the lowest score and was given to participants who did not complete any of the modules or submitted an assignment.

Figure 2 shows the band scores of those participants who completed the course modules $90-100 \%$. There were students who had completed all the course requirements (Band 10), still some students lacked active participation in forum discussions (Band 9) or failed to submit one (Band 8) or all three (Band 4) of independent assignments, or else submitting two successful assignments, completing $90 \%$ of the modules without contribution in forum discussions (Band 7). Similar range of reasons for the minor contribution were presented as listed previously.

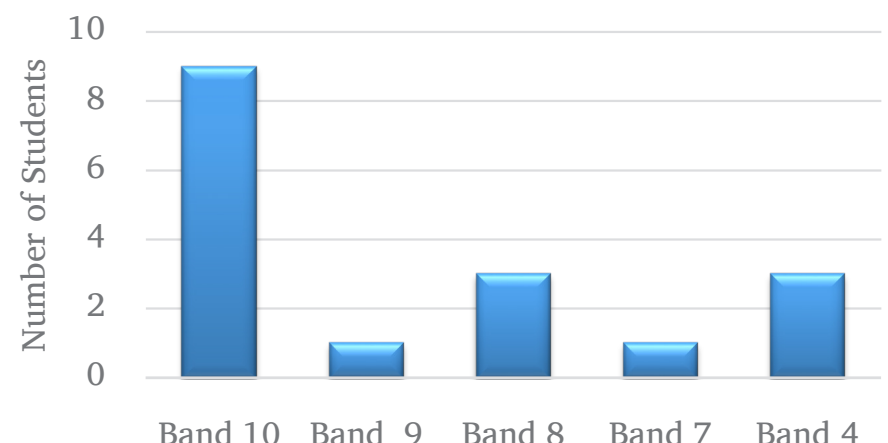

Figure 2. Students Who Completed the Online Modules (90 - 100\%) and Their Received Band Scores

As the smart learning environment lets students improve their performance for individual activities of each module, providing immediate feedback (clicking the button Show Feedback), correct answers (clicking the button Show Answers) and opportunity to complete the required task repeatedly (clicking the button Try Again), the majority of students stated that they tried to improve their module completion rate up to $100 \%$ or in the range from 90 to $100 \%$. 
Smart learning is related to anytime and anywhere by using an advanced electronic device. A new module was opened on Monday, available from that time on until the end of the course; the majority of respondents admitted that they explored the requirements of the week on Mondays, contributed and/or followed weekly forum discussions all week long, but attempted to complete their weekly units later in the week, on Sunday, or postponed accomplishing a week or more later. The students' chosen study time ranged from early mornings, afternoons, evenings till late night hours. Location wise, most of the students chose to study at home, although such study places as a university building, library, café, public transportation (buses, trains) were indicated.

"Sometimes I forgot that I had to do the online course, because I am used to lessons in real life, going to university", wrote one student in the questionnaire. To characterise the participants' practice and time management strategies, first, the satisfaction of one's own time management while participating in the online course mostly ranged from "to a very great extent" to "to some extent", according to the Likert scale used in the study, but those students who failed the course acknowledged that they were satisfied "to a small extent" or "not at all". Second, students' time management was considerably challenged and required advanced planning and change of study habits to succeed in the online learning process, too. It was revealed that multitasking did not directly reduce students' learning performance, it affected the efficiency of study time. Thus, it can be concluded that smart learning anytime and anywhere is not favourable for any learner; there would be students who would need supportive guidance and controlled conditions.

Finally, the reflections of the online course moderators were collected to triangulate the data and find out their opinion on students' time management habits and performance quality. The moderators managed to form an overall positive impression of Latvian students' activity and performance quality. The added value was the opportunity to learn about Latvian pre-service teachers' awareness and perception of opportunities offered by latest technologies and technology-enhanced language learning which students revealed in weekly forum discussions and in their designed lesson plans, thus demonstrating the gained knowledge and skills in productive real-world contexts. Having enthusiasm for technologyenhanced language learning, the course moderators faced differences between their expectations and reality. As a result, certain strategies could be considered to improve the students' performance and course completion rate, e.g. by allowing participants to demonstrate valuable competences in various synchronous and asynchronous learning formats and online teamwork, spending time on problem-solving activities in smaller groups or implementing frequent assessment. 


\section{Conclusions}

There is much to be learned from existing researches on various practices on open online and technology-enhanced learning. A priceless opportunity is offering future English language teachers theoretical, methodological and practical learning journeys to extend knowledge and master skills for integrating information and communication technologies in the language teaching and learning process as a modern must. The participation of pre-service teachers in the online course as a hands-on practice study component in a real-life context led to the following conclusions:

1. A blended learning, combining offline and online learning, rather than a totally online learning approach is meaningful and beneficial for university students. Even when planning to reduce expenses for teaching smaller groups of students at the university, face-to-face interaction meetings have to be organised.

2. When studying in a smart learning environment as a part of study programme to achieve particular learning outcomes and to avoid working alone together, a contact with academic staff can heighten a sense of purpose, control over what students are learning and strengthen support when needed.

3. The time for synchronous sessions has to be planned rationally to have a high participation rate; the peculiarities of target groups have to be a matter for careful and detailed consideration.

4. A lack of knowledge on how to use digital tools, online learning platforms for study purposes, an overload in offline and online studies, a lack of time or limited time management skills, and a lack of intention to complete a course are the key reasons for withdrawing from online courses. To avoid it, the possible challenges should be discussed with the target group initially and the improvement of students' time management skills and study habits should be encouraged.

It is noteworthy to indicate that the described online course used for this study was held some time before the extreme situation connected with the outbreak of the pandemic coronavirus. Flexibility for distance education was a key when planning and organising a study process, which had to be proceeded. The community of practice ensured that educators had resources and skills to teach and support the learning. The previously gained experience studying autonomously online using synchronous learning tools and smart learning environments turned out to be an advantage. However, there was no guarantee that all the students managed to complete their university courses studying in safe home settings; many factors that affected study course completion rates among students interacted, time management, study habits, challenges in the process of studying are among them. 


\section{References}

Claessens, B. J. C., van Eerde, W, Rutte, C G. \& Roe, R. A. (2007). A Review of the Time Management Literature. Personal Review, 36(2), 255-276.

Council of Europe. (2019). Digital Citizenship Education Handbook. Being Online. Wellbeing Online. Rights Online. Strasbourg: Council of Europe.

Daniela, L., Kalnina, D., \& Strods, R. (2017). An Overview of Effectiveness of Technologyenhanced Learning (TEL). International Journal of Knowledge Society Research, 8(1), 79-91. DOI: 10.4018/IJKSR.2017010105.

Golonka, E. M., Bowles, A. R., Frank, V. M., Richardson, D. L., \& Freynik, S. F. (2014). Technologies for Foreign Language Learning: A Review of Technology Types and Their Effectiveness. Computer Assisted Language Learning, 27, 70-105.

Hwang, G. J. (2014). Definition, Framework and Research Issues of Smart Learning Environments - a Context-aware Ubiquitous Learning Perspective. Smart Learning Environments, 1(4), 1-14. DOI https://doi.org/10.1186/s40561-014-0004-5.

Koller, D., Ng, A., \& Chen, Z. (2013, June 3). Retention and Intention in Massive Open Online Courses: In Depth. Educause Review. Retrieved from https://er.educause.edu/ articles/2013/6/retention-and-intention-in-massive-open-online-courses-in-depth.

Lakein, A. (1973). How to Get Control of Your Time and Life. New York: Signet Books.

Murray, S. (2019, March 4). MOOCs Struggle to Lift Rock-bottom Completion Rates. Financial Times. Retrieved from https://www.ft.com/content/60e90be2-1a7711e9-b191-175523b59d1d.

Reich, J. (2014, December 8). MOOC Completion and Retention in the Context of Student Intent. Educause Review. Retrieved from https://er.educause.edu/articles/2014/12/ mooc-completion-and-retention-in-the-context-of-student-intent.

Reich, J. \& Ruiperez-Valiente, J. A. (2019). The MOOC Pivot: From Teaching the World to Online Professional Degrees. Science, 363(6423), 130-131. DOI: 10.1126/science. aav7958.

Thompson, P. (2017.) Communication Technology Use and Study Skills. Active Learning in Higher Education, 18(3), 257-270.

van den Berghe, R., Verhagen, J., Oudgenoeg-Paz, O., van der Ven, S., \& Leseman, P. (2019). Social Robots for Language Learning: A Review. Review of Educational Research, 89(2), 259-295. 